\title{
Política curricular como política cultural: uma abordagem metodológica de pesquisa
}

\author{
Ozerina Victor de Oliveira
}

Universidade Federal de M ato Grosso, Instituto de Educação

U niversidade Estadual do Rio de Janeiro, Programa de Pós-Graduação em Educação

\section{Denise de Souza Destro}

Secretaria M unicipal de Educação de Juiz de Fora

U niversidade Estadual do Rio de Janeiro, Programa de Pós-Graduação em Educação

\section{Introdução}

Indignados com os resultados insatisfatórios da escolarização, especialmente no ensino fundamental, alguns pesquisadores brasileiros têm abordado a questão em suas implicações para a política curricular. Seus estudos denunciam que, no que tange às políticas curriculares, o fracasso escolar persiste porque estas têm sido prescritivas, homogeneizantes, centralizadas no Estado, porque demonstram um distanciamento entre avanços teóricos e avanços práticos, e porque apresentam sintomas da globalização das políticas educacionais.

A abordagem metodológica desses estudos tem potencial para mostrar fundamentalmente o poder das chamadas "políticas oficiais" ou "hegemônicas" e das relações políticas no sentido global/local sobre os currículos escolares. Embora essa denúncia seja indispensável para as análises críticas do currículo, já não nos parece mais suficiente, uma vez que nela predomina uma perspectiva vertical de controle sobre os currículos em um contexto que requer a adoção de uma postura contra-hegemônica, diante de um qua- dro teórico de avanço no campo curricular, consubstanciado pela ampliação do que se entende por campo político.

A ampliação do campo político, em particular, trouxe a discussão das relações de poder até o que tradicionalmente tem sido denominado "campo cultural" ou "dimensão cultural" da realidade social, tornando possível assim a absorção das contribuições de estudos pós-coloniais para estudos dos processos analíticos de pesquisas em políticas curriculares. ${ }^{1}$

${ }^{1}$ Conforme Macedo (2002, p. 9-10), “em linhas gerais, o pós-colonialismo estudaria as relações entre a Europa e as sociedades por ela colonizadas no período moderno. As discussões que, no entanto, vêm-se travando no campo dos estudos pós-coloniais transcendem essa definição, englobando tanto a experiência de minorias em países centrais quanto as formas de subjugação neocoloniais advindas da expansão do capitalismo e da globalização. Ou seja, inúmeros estudos utilizam-se da expressão pós-colonialismo, significando uma posição contra o imperialismo ou o americanismo. [...] resistência a todas as formas de globalismos $[\ldots] "$ 
Nesse ínterim, indagamos sobre os possíveis caminhos para se desenvolverem pesquisas em políticas curriculares: que abordagens metodológicas em política curricular dariam inteligibilidade às relações de poder implicadas em relações culturais constituintes dessas políticas? Como analisar uma política curricular no sentido local/global? Como visualizar movimentos contra-hegemônicos de políticas curriculares em contextos históricos em condição colonial?

As respostas a serem dadas a tais questões nos parecem possíveis pelos subsídios fornecidos por pesquisadores brasileiros a partir de estudos pós-coloniais que fornecem suportes para o campo do currículo, e por contribuições de pesquisas realizadas em outros países, as quais analisam e procuram definir o que seja política curricular. Esses subsídios têm discutido as implicações de resultados insatisfatórios na escolarização e suas relações com a política curricular.

A partir dessas possibilidades, nosso propósito é problematizar e destacar contribuições de análises de políticas curriculares no Brasil, situar a problemática no contexto das discussões de estudos que dêem centralidade à cultura em processos analíticos e colocar em discussão o que tem sido definido como política curricular para que, com isso, possamos apontar características para uma abordagem metodológica de pesquisa em política curricular que dê inteligibilidade a processos contra-hegemônicos em políticas curriculares, que dê visibilidade às implicações culturais em sua constituição e, enfim, que desloque o processo analítico hegemônico, ou seja, que possibilite analisar a política curricular no sentido local/global.

\section{Estudos de políticas curriculares e suas implicações metodológicas}

Na última década do século XX, alguns educadores brasileiros demonstraram suas preocupações com os resultados da escolarização da maioria da população e desenvolveram estudos que vêm nos mostrar os vínculos entre esses resultados insatisfatórios e as políticas curriculares implementadas no país.
Compartilhando da mesma preocupação, procuraremos corroborar contribuições proporcionadas por esses estudos para pensarmos as políticas curriculares, bem como os direcionamentos metodológicos que deles podem ser abstraídos em termos de pesquisa no campo do currículo.

Os estudos aqui considerados destacam as políticas curriculares nacionais sem deixar de relacionálas aos problemas internos do campo do currículo e das políticas globais.

Elba Siqueira de Sá Barreto (2000, p. 15) faz uma análise de propostas curriculares implementadas por práticas políticas de governos nas duas últimas décadas do século XX no Brasil. Em seu estudo, ela admite que, apesar de as propostas terem assumido um discurso democrático,

\footnotetext{
[...] as características de insucesso escolar da maioria da população pouco se alteraram, visto que as mudanças preconizadas e implementadas no período não afetaram profundamente as questões estruturais dos sistemas públicos de ensino, responsáveis, em proporção significativa, pelos seus altos índices de fracasso.
}

A pesquisadora associa esses resultados às políticas educacionais públicas, por elas serem prescritivas, homogeneizantes e centralizadas no Estado, e também devido aos seus mecanismos de divulgação (livros didáticos), implementação (capacitação de docentes à distância) e controle (avaliação externa). Apesar da autora não fazer uso da denominação "políticas curriculares públicas", entendemos, no entanto, que as mesmas características podem ser igualmente atribuídas a tais políticas.

Contudo, a prescrição, a homogeneização e a centralização não têm sido problemas restritos às fronteiras nacionais. Em consonância com as políticas hegemônicas da década de 1990, existe aí uma forte relação com as políticas globais.

Antonio F. B. Moreira e Elizabeth Macedo (2000, p.108), em estudo revisionista sobre transferência educacional, somam seus esforços ao estudo de Barreto, pois, além de relacionarem a insatisfação no 
que tange aos resultados da escolarização com o distanciamento entre teoria e prática no campo do currículo, destacam com propriedade a relação existente entre políticas educacionais nacionais e globais. Eles reconhecem que "ainda que tenhamos avançado na produção de conhecimento teórico, a prática pedagógica, na maioria das nossas escolas, ainda não sofreu modificações mais substantivas”. E, oportunamente, situam essa problemática no contexto de globalização das políticas educacionais, evidenciando a complexidade da questão e suas estreitas relações com o campo do currículo, o que pode ser ilustrado com a seguinte afirmação: "se no plano teórico talvez estejamos menos susceptíveis às importações instrumentais, no âmbito das políticas educacionais sentimos com clareza a força do modelo neoliberal internacional, definindo os rumos do currículo e do processo de escolarização no Brasil”" (idem, p. 106). A força do modelo neoliberal, segundo os mesmos, pode ser visualizada pela presença do Banco Mundial na definição de políticas educativas, fazendo prevalecer a lógica financeira sobre a social, subordinando assim a educação à racionalidade econômica, por medidas que implantam os princípios neoliberais na educação, tornando-a mais competitiva.

Anteriormente, Moreira (1998, p. 30) já havia sugerido uma forte relação entre desafios educacionais, teoria curricular e política curricular. Ao fazer um balanço da crise da teoria crítica de currículo, colocando como sintoma dessa crise o distanciamento entre avanços teóricos e avanços práticos, ele recomenda que "os curriculistas atuem nas diferentes instâncias da prática curricular, participando da elaboração de políticas públicas de currículo, acompanhando a implementação das propostas e realizando estudos nas escolas que avaliem essa implementação". Dessa forma, esse autor coloca em pauta a necessidade não só de os pesquisadores em currículo atuarem em políticas públicas como fundamentalmente de direcionarem seus esforços de pesquisa para as políticas curriculares.

$\mathrm{Na}$ mesma perspectiva desses autores, Corinta M. G. Geraldi (2000) traz contribuições significativas para avançarmos em relação à questão em pauta. Essa pesquisadora reforça a compreensão dos vínculos entre política curricular e globalização, a necessidade de articulação teoria/prática no campo do currículo, e de se realizarem pesquisas em políticas curriculares, sugerindo porém que essas pesquisas dêem ênfase às resistências que ocorrem ao processo de globalização. Em tal estudo, a pesquisadora parte da problemática de que, nas três últimas décadas do século XX, as escolas, "mesmo que de forma incompleta, não mecânica nem linear", têm desencadeado uma educação para a alienação ao trabalho. Ela defende a tese de que são os grandes grupos internacionais que estão planejando a educação, por meio da criação de uma rede de controle da educação; rede que, para realizar-se, precisa da avaliação, e esta, por sua vez, necessita de uma referencia básica que "possa ser efetivada em nível nacional" (p. 200), daí a existência dos Parâmetros Curriculares Nacionais. É nesse contexto, portanto, que a autora situa os Parâmetros Curriculares Nacionais para o Ensino Fundamental, considerando-os um exemplo de gestão de políticas curriculares oficiais globais. Geraldi destaca, sobretudo, a existência de contradições. No que diz respeito às políticas curriculares, salienta a existência de alternativas às propostas hegemônicas oficiais, entendendo que estas se encontram presentes nas escolas, no "currículo em ação".

Todos esses estudos indicam, sob os aspectos aqui destacados, uma clara insatisfação com os resultados da escolarização no ensino fundamental no Brasil, sendo que estão relacionados com a política curricular, e esta, com as implicações da globalização na política educacional. As contribuições desses estudos, embora significativas, não respondem mais às exigências do atual contexto social e aos avanços teóricos no campo do currículo. As abordagens dessas pesquisas (mesmo a de Geraldi, que destaca as alternativas produzidas localmente) são desenvolvidas no sentido global/local, mostrando, fundamentalmente, o poder das relações hegemônicas.

Alertamos assim para a carência de centralidade dos processos de contra-hegemonia em estudos de 
política curricular, sem, no entanto, deixarmos de reconhecer as relações hegemônicas. Entendemos que essa abordagem pode ser pensada a partir de estudos que possuam uma lógica espacial que não dicotomize nem polarize as relações entre o global e o local, e a partir daqueles que dêem centralidade à cultura em processos analíticos. Visualizamos essas possibilidades em Hall (1997), Said (1978), Santos e Avritzer (2002) e Santos $(2002,2003)$.

\section{A centralidade da cultura e o espaço para definição da política curricular como política cultural}

Procuramos aqui tratar a possibilidade metodológica identificada nos estudos já expostos, construindo um espaço a partir do qual possamos visualizar as políticas curriculares na perspectiva da contrahegemonia. A construção desse espaço tornou-se possível com a produção intelectual acima mencionada, à medida que seus autores explicitam a centralidade da cultura em termos epistemológicos, ampliam o campo político mostrando a conexão entre cultura e política, e constroem uma lógica espacial não-binária para a compreensão das inter-relações entre o "global" e o "local".

Toda essa produção nos diz que não é possível mais abordarmos as relações entre identidades culturais e globalização sem o pressuposto de que "as revoluções da cultura em nível global causam impacto sobre os modos de viver, sobre os sentidos que as pessoas dão à vida, sobre suas aspirações para o futuro - sobre a cultura num sentido mais local" (Hall, 1997, p. 18). No entanto, não é possível também deixar de reconhecer que isso não significa que esses condicionantes sejam inexoráveis, mas que as implicações entre global/local e vice-versa constituem complexos processos culturais.

Visualizamos esses processos culturais a partir do momento em que exercitamos nossa percepção sobre as relações entre culturas locais e globais, verificando que a intensificação dos processos de globalização tem ocasionado deslocamentos culturais, donde se evidencia que o local não possui uma identidade “objetiva”, nem tampouco está numa condição de dependência em relação ao global. Isto significa que a globalização não ocasiona um processo de homogeneização cultural, mas o mais provável é que ela desencadeie identidades híbridas.

Essa não correspondência direta de identidades com culturas locais ou globais dá margem para pensarmos em culturas híbridas e possivelmente para pensarmos em diferentes relações de poder, uma vez que se escapa da verticalidade da determinação de um poder global sobre o local. Significa também que, a partir dessas implicações, não haverá mais um "global" ou um "local" legítimo, já que os processos culturais contemporâneos e as conseqüentes relações de poder neles produzidas passam a interferir na constituição de ambos (Hall, 1997; Santos, 2003).

Parece-nos que esse entendimento é possível a partir do que tem sido denominado "virada cultural". Apoiando-nos em Hall (1997), podemos defini-la como uma abordagem social contemporânea que, por meio da reconfiguração de elementos, toma a cultura como o aspecto epistemológico central na análise social. Nela a cultura passa de variável dependente para condição constitutiva da vida social e conseqüentemente dos objetos de estudo - em especial no campo da educação. A partir de então, repensam-se radicalmente as articulações mútuas entre fatores econômicos, culturais e políticos, obrigando-nos a repensar também a articulação entre os fatores materiais e simbólicos nas pesquisas educacionais, dando centralidade à cultura. A "virada cultural" é, portanto, a defesa da centralidade da cultura em termos epistemológicos. Como afirma Hall,

\footnotetext{
[...] a cultura é agora um dos elementos mais dinâmicos -e mais imprevisíveis - da mudança histórica do novo milênio. Não deve nos surpreender, então, que as lutas pelo poder sejam, crescentemente, simbólicas e discursivas, ao invés de tomar, simplesmente, uma forma física e "política cultural". (1997, p. 20)
}

Assim, com a centralidade da cultura, o autor nos sugere igualmente um repensar do campo políti- 
co, o que significa visualizar as complexas imbricações entre o "cultural" e o "político".

A ampliação do campo político foi desencadeada por Williams (apud Santos, 2002, p. 53), ao demonstrar que a política envolve "uma disputa sobre um conjunto de significações culturais." Por essa ampliação, podemos perceber a relevância da cultura para compreensão das relações de poder; relevância que, em tempos de globalização no capitalismo neoliberal,

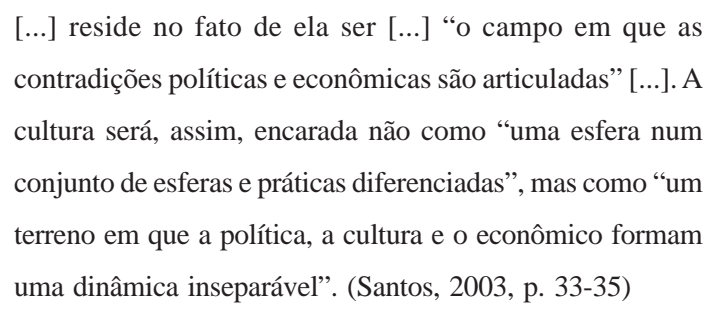

Nessa perspectiva, tanto a política como a cultura perdem suas fronteiras na medida em que são desterritorializadas, configurando-se, desse modo, uma conexão entre ambas, em que a própria política passa a ser vista como política cultural. Como implicação da centralidade, a cultura é entendida como um campo de lutas e contradições (Hall, 1997).

No contexto das globalizações, a centralidade da cultura e a ampliação do campo político chama nossa atenção para possíveis itinerários contra-hegemônicos que estejam ocorrendo em espaços locais, ou seja, para a contribuição de estudos que destacam o poder local em experiências históricas distintas, identificando esse poder a partir da identificação de forças culturais (Santos \& Avritzer, 2002; Santos, 2003).

Uma perspectiva de pesquisa assim concebida pressupõe a existência de uma globalização contrahegemônica, pois não só descarta que "o global acontece localmente", mas coloca como pauta de luta que "é preciso fazer com que o local contra-hegemônico também aconteça globalmente" (Santos, 2002, p. 74).

As relações local/global e cultura/política parecemnos ainda mais evidentes quando nos deparamos com a radicalidade da geografia imaginativa dos chamados estudos pós-colonialistas, mais especificamente os estudos de Said. Esse estudioso questiona as regras que constroem os espaços sociais, dividindo-os em Ocidente e Oriente, sugerindo que "as fronteiras geográficas acompanham as sociais, étnicas e culturais de um modo previsível" (Said, 1978, p. 64). Nessa perspectiva, a geografia imaginativa desse autor indica que há algo mais entre local e global do que nos têm dito os estudos que até então os abordaram.

Said define o orientalismo como um processo de identificação, julgamento, descrição, disciplinamento, ilustração e governo do Oriente pelo Ocidente. Enfim, como um exercício de força cultural do segundo sobre o primeiro. A partir desse estudo é possível dizer que a demarcação do espaço geográfico das fronteiras não possui apenas um caráter físico, mas simbólico, portanto, cultural.

Esse entendimento, por sua vez, leva-nos a crer que as demarcações entre o "global" e o "local" adquiriram coerência e consistência com o tempo porque pesquisadores têm se dedicado constantemente a isso. Tem havido uma obliteração do local, uma vez que ele não tem falado por si, quem tem se pronunciado é o global. O local tem sido o que o global diz que ele é, e cada vez que se pronuncia que o local é instituído pelo global define-se sua anatomia, nega-se a sua autonomia e o seu autogoverno, faz-se uma oposição binária entre ambos, aumentando com isso a fenda que separa os dois e restringindo o espaço do local - daí a condição colonial da relação entre ambos. Portanto, as demarcações entre o "local" e o "global" são fruto de construções históricas, conflitos e lutas.

A nosso ver, as perspectivas de Hall (1997) e Said (1978), bem como as de Santos e Avritzer (2002) e Santos (2003), não dicotomizam, não polarizam e nem criam uma hierarquia nas relações de poder entre o "global" e o "local". Em consonância com esse modo de pensar, consideramos de fundamental importância que, para fins analíticos, a definição de tópicos de investigação ocorra em termos locais, e não globais.

Para além da centralidade da cultura e da ampliação do campo político, temos agora, especialmente 
com a geografia imaginativa de Said, uma lógica espacial não binária para a compreensão das conexões local/global.

Tendo em vista essas contribuições, entendemos que avançar na compreensão e na implementação de políticas curriculares com a perspectiva de enfrentamento dos resultados insatisfatórios da escolarização significa desenvolvermos estudos que façam um deslocamento na abordagem metodológica até hoje hegemônica, com o intuito de se retirar o foco do controle vertical e do sentido global/local para visualizarmos o movimento de contra-hegemonia nas relações de poder estruturadoras dessas políticas curriculares. É preciso que se desenvolvam pesquisas em política curricular capazes de identificar, por meio da tradução de forças culturais, itinerários contra-hegemônicos que estejam ocorrendo em espaços locais e em experiências históricas distintas.

Essas construções teóricas, embora ainda não suficientemente exploradas, têm proporcionado avanços teóricos no que tange ao campo do currículo. Costa (1999, p. 37-38) sintetiza com propriedade parte desses avanços, definindo currículo "como um campo em que estão em jogo múltiplos elementos, implicados em relação de poder, sendo a escola e o currículo territórios de produção, circulação e consolidação de significados".

Tal qual essa autora, não pretendemos estabelecer aqui uma relação entre currículo e cultura na perspectiva de que a escola trabalha com o conhecimento (que é cultura e, portanto, a escola trabalha com cultura), mas sim quebrar as fronteiras estabelecidas entre ambos, entendendo o currículo como um terreno privilegiado da política cultural.

Torna-se oportuno, neste momento, conceituar política curricular a partir da definição de política cultural de Álvarez et al. (apud Santos, 2003, p. 39). Álvarez define cultural politics como "o processo acionado quando o conjunto de atores sociais formados por e incorporando diferentes significados e práticas culturais, entram em conflito entre si."

A definição de política curricular como política cultural até agora apresentada ainda não nos parece suficiente para respondermos às questões por nós apresentadas inicialmente. Construir possibilidades metodológicas a partir dessa compreensão requer necessariamente uma revisão do que tem sido definido como política curricular, com o intuito de destacar elementos para uma abordagem analítica de pesquisa em política curricular entendida como política cultural. Afinal, que definições têm sido dadas à política curricular? O que temos obtido em significação com elas? Como a política curricular ocorre? Qual seu processo de construção? Quais são seus protagonistas? Como investigá-la? É a partir dessas indagações que desenvolveremos a próxima seção.

\section{Definições de política curricular e seu potencial metodológico para a investigação da política curricular como política cultural}

O tema das políticas curriculares tem ficado à sombra do tema das políticas educacionais. No Brasil, somente a partir da década de 1990, por meio dos estudos expostos anteriormente, é que esse assunto foi ganhando visibilidade na literatura acadêmica. Em conseqüência, é fora do país que encontramos pesquisadores que têm discutido com mais especificidade e profundidade essa temática. Dispomos assim dos estudos de Suárez (1995), Gimeno Sacristán (1998), Bowe e Ball (1992) e Ball (1997, 1998), para obtermos elementos com o propósito de definição e construção metodológica de pesquisa em política curricular com uma abordagem que favoreça as necessidades anteriormente enunciadas.

Suárez (1995, p. 110), ao tratar das relações entre políticas públicas e reforma educacional na Argentina, afirma que

\footnotetext{
[...] a formulação e implementação de políticas curriculares não são neutras, nem muito menos são um asséptico processo de elaboração e instrumentação técnicas. No fundamental, são o resultado sintético de um (muitas vezes silenciado e oculto) processo de debate ou de luta entre posicionamentos, interesses e projetos sociais, políticos, culturais e pedagógicos opostos e, sobretudo, antagônicos.
} 
O processo de determinação dessas políticas não é, de forma alguma, unívoco, nem tampouco está isento de contradições e de tensões.

A contribuição central desse autor consiste na caracterização da política curricular enquanto síntese de um processo de luta entre projetos sociais com interesses antagônicos, implicando contradições.

Do mesmo modo, Gimeno Sacristán (1998, p. 109), ao discutir a reforma curricular ocorrida na Espanha, parte do pressuposto de que as teorias curriculares são elaborações parciais, insuficientes para compreender a complexidade das práticas escolares. Em função dessa análise, propõe uma concepção processual de currículo e procura situar a política curricular como elo entre interesses políticos, teorias curriculares e práticas escolares. Define política curricular como "um aspecto específico da política educativa, que estabelece a forma de selecionar, ordenar e mudar o currículo dentro do sistema educativo, tornando claro o poder e a autonomia que diferentes agentes têm sobre ele".

Essa compreensão é importante no momento em que salienta, diferentemente de Suárez, a existência de instâncias distintas que intervêm no processo de construção das políticas curriculares. Isso ocorre à medida que reconhece as relações entre Estado, política educativa, sistema educacional e práticas pedagógicas. Não obstante, é a transposição das características do que Sacristán (1998, p. 101) define como processo curricular para política curricular que ajuda no entendimento dessa última. Assim como no sistema curricular, na política curricular

[...] as decisões não se produzem linearmente concatenadas, obedecendo a uma suposta diretriz, nem são frutos de uma coerência ou expressão de uma mesma racionalidade. Não são estratos de decisões dependentes umas de outras, em estrita relação hierárquica ou de determinação mecânica e com lúcida coerência para com determinados fins. [...] São instâncias que atuam convergentemente na definição da prática pedagógica.
Dessa elucidação sobre política curricular podemos destacar as possibilidades de ruptura nela existentes, uma vez que o autor evidencia o caráter conflitivo e contraditório da mesma, destacando a existência de decisões independentes e insubordinação, bem como de práticas convergentes, características que, em conjunto, assinalam para a existência de hibridismo nas relações de poder presentes em políticas curriculares.

Apesar das contribuições fornecidas por Suarez e Gimeno Sacristán, o primeiro não discute a política curricular em termos analíticos, e o segundo, apesar de avançar ampliando a caracterização e de defender uma compreensão de política curricular que pressupõe hibridismo no que tange às relações de poder, não explora radicalmente as possibilidades já existentes, especialmente no que diz respeito à definição de uma metodologia de pesquisa em política curricular dando centralidade à cultura. Isso ocorre porque, ao explorar o processo curricular, Gimeno Sacristán o divide em diferentes níveis ou fases - currículo prescrito, currículo apresentado aos professores, currículo moldado pelos professores, currículo em ação e currículo avaliado -, fragilizando, a nosso ver, o caráter processual e de totalidade da política curricular. Além disso, ressalta o currículo prescrito como um instrumento da política curricular, perdendo novamente o caráter processual desta, passando a compreendê-la como algo externo ao que denomina currículo prescrito, e, do mesmo modo, como algo externo às escolas.

Apesar desses autores fornecerem subsídios teóricos em relação à política curricular, entendemos que suas definições e direcionamentos não atendem às exigências presentes na realidade educacional contemporânea, a qual se encontra situada em um contexto em que a centralidade da cultura, em termos epistemológicos, assim como a ampliação do campo político e a lógica espacial não-binária vêm requerer uma abordagem metodológica sem dicotomias e polarizações, de modo que potencialize as complexas imbricações entre local/global e entre o fator econômico, o político e o cultural. 
Esses estudos, no entanto, não são os únicos que constam no campo do currículo. Nele encontramos também as concepções de política e de método de pesquisa em política curricular trabalhadas por Bowe e Ball (1992) e por Ball (1997, 1998). Ao nosso ver, tais estudos entram em consonância com as questões anteriormente estabelecidas, tanto pela defesa da política curricular como processo político em construção quanto pelo modo como sugerem pesquisas em políticas curriculares.

Em estudo revisionista do campo da política curricular, Bowe e Ball (1992) e Ball (1997, 1998) denunciam as pesquisas desse campo por fragmentarem o processo político, ao focalizarem ora a produção, ora a implementação das políticas. Para eles, as pesquisas que focalizam a produção da política ficam restritas à dimensão macro da realidade social, silenciando as vozes daqueles envolvidos na prática pedagógica, deixando-os à margem da política curricular. Já as pesquisas que focalizam a implementação, apesar de sua importância por darem evidência às vozes silenciadas e por colocarem seu caráter subversivo, não trabalham os condicionantes históricos dessas vozes. Como conseqüências negativas, separam produção e implementação, teoria e prática, e constroem uma visão linear do processo político: ora de cima para baixo, ora de baixo para cima.

Esses autores também fazem críticas à teoria de controle estatal na política curricular, ou seja, à teoria de que o Estado define linearmente essas políticas. $\mathrm{Na}$ crítica, desconstroem a visão de que a produção política é separada e distante da implementação; de que a política se realiza por uma cadeia de implementadores legalmente definidos; de que ela seja imposta, e de que os definidores da política educacional estão distantes da realidade educacional e por isso não conseguem controlá-lo. Enfim, rejeitam a concepção linear e fragmentada do processo político.

Em contraposição, desenvolvem estudos sobre política curricular, e a partir de então mostram que a forma como o processo político ocorre resulta da combinação entre métodos administrativos, condicionantes históricos e manobras políticas, implicando o
Estado, a burocracia estatal e os conflitos políticos contínuos ao acesso desse processo político.

Dessas análises, os mesmos concluem, ainda, que a política curricular não é imposta, uma vez que é constituída por textos que, sendo processos simbólicos, são constantemente contextualizados e recontextualizados de modo subversivo no momento da implementação e da produção. Em consequiência, sugerem que as políticas definidas em nível nacional são também significativamente modificadas em nível local.

Como implicação de seus estudos, definem ainda o processo político como aquele que emerge de uma contínua interação entre contextos inter-relacionados e entre textos e contextos. Dessa definição, propõem um modelo analítico para pesquisa em política curricular que seja representativo do ciclo político, que dê uma representação holística ao processo político, de forma que seja concebido como um processo cíclico, conflituoso, ambíguo, plural, contraditório e histórico.

Segundo Bowe e Ball (1992), as análises em política curricular, para terem validade política e teórica, devem considerar os três contextos primários da política curricular: o contexto de influência, o contexto de produção do texto político e o contexto da prática, todos vistos como inter-relacionados e como textos, uma vez que produtores de significados. O primeiro consiste no espaço-tempo em que os conceitoschave são estabelecidos para gerar o discurso político inicial. O segundo toma a forma de textos legais, oficiais, documentos e textos interpretativos, que podem ser contraditórios tanto internamente quanto na intertextualidade, na qual diferentes grupos competem para controlar a representação e o propósito da política. Já o terceiro consiste nas possibilidades e limites materiais e simbólicos, e na leitura daqueles que implementam a política. Esse contexto é entendido como espaço de origem e de endereçamento da política curricular.

Temos, pois, a partir desses autores, um avanço significativo na compreensão do que seja política curricular e na construção de uma abordagem analítica 
dessa política como política cultural. Primeiro, porque não só definem a política curricular como explicitam seu processo de construção - e, o que é mais importante, sem dicotomizá-lo. Segundo, porque dão voz a todos os agentes políticos sem criar hierarquias entre eles. Terceiro, e em consequiência dos anteriores, reconhecem no processo político a conexão entre local/global à medida que destacam não só o movimento do global para o local, mas o inverso também, considerando assim a lógica espacial não-binária. Quarto, e o que é de fundamental importância para os objetivos propostos em nosso estudo, ao destacarem os conflitos políticos existentes nos diferentes contextos de produção da política curricular e ao definirem esses contextos como textos, portanto, como construções simbólicas, possibilitam não só a visualização de conflitos culturais no processo de construção da política curricular como também de movimentos contra-hegemônicos no processo político, abrindo caminhos assim para considerarmos metodologicamente tanto a centralidade da cultura como a ampliação do campo político.

\section{Considerações finais}

Nos dias de hoje, estamos com dificuldades para sobreviver às consequiências das arbitrárias distinções que temos feito entre Estado e cotidiano, política e cultura, global e local, material e simbólico. Afinal, o Estado, a política, o global e o material não têm sido os únicos protagonistas ativos da História, principalmente quando pensamos em contra-hegemonia nas políticas curriculares. A possibilidade dessa afirmação só ganha sentido quando pressupomos que a vida social e os objetos de estudo dela "recortados" são constituídos por complexos processos culturais que articulam o material e o simbólico, a economia, a política e a cultura; quando pressupomos que as relações de poder não são fixas, mas resultam da disputa por significações culturais, e que o espaço dessas disputas não está demarcado por posições binárias fixas ou dicotômicas, mas são frutos de construções históricas. Enfim, consideramos a centralidade da cul- tura em termos epistemológicos, a ampliação do campo político e a lógica espacial não-binária dos póscolonialistas.

Tendo em vista as considerações expostas neste estudo, definimos política curricular como um processo histórico em que diferentes protagonistas, imbuídos de seus projetos culturais/sociais, produzem tensões em torno da produção, circulação e consolidação de significados no currículo escolar. Por isso, entendemos a política curricular como uma política cultural.

A partir dessa definição, sugerimos alguns pontos que podem ser levados em consideração ao se desenvolverem pesquisas em política curricular, com o intuito de identificar itinerários contra-hegemônicos que possam estar ocorrendo por forças culturais em experiências históricas específicas.

Sugerimos o deslocamento da abordagem metodológica hegemônica, ou seja, da perspectiva global/ local para a perspectiva local/global. Isso porque os processos e forças culturais são mais bem visualizados em situações históricas especificas. Portanto, a melhor forma de definir-se uma temática para estudo em política curricular é fazê-la localmente. Alertamos, no entanto, que o deslocamento deve ocorrer somente no sentido da perspectiva, do ponto de partida, sem contudo isolar, polarizar ou inverter a verticalização em relação ao contexto global, para não cairmos em equívoco, perdendo com isso a perspectiva processual e histórica da política.

Consideramos um erro focalizar produção ou implementação, Estado ou cotidiano nas pesquisas em política curricular, sob pena de dicotomizarmos e polarizarmos o processo político. Isso porque a política curricular não coincide com as relações de poder travadas no processo político, mas sim implica diferentes relações de poder; significa, portanto, o efeito dessas relações.

Certamente nossas considerações não teriam existência sem as contribuições dos autores que problematizaram o controle na política curricular e daqueles que a discutiram sistematicamente, especialmente os estudos de Gimeno Sacristán e Ball. Mas, 
apesar dos estudos deste último proporcionarem avanços significativos para se pensar e pesquisar política curricular entendida como política cultural, reconhecemos que eles "somente" abrem possibilidades para se explorar as relações de poder presentes em processos culturais constituidores da política curricular, e não os definem concretamente nem exploram essas relações. Compreendemos, portanto, que existe uma possibilidade de análise em política curricular com urgência de ser trabalhada se quisermos dar um novo alento no tocante à questão cultural.

A validade dessa possibilidade, no entanto, só poderá ser visualizada de modo mais preciso pragmaticamente, em processos empíricos de pesquisa, os quais, a nosso ver, podem ser desenvolvidos levando-se em conta as seguintes questões: Como foi construída a política curricular? Quem são os protagonistas do processo político? Quais foram suas estratégias, seus sucessos, suas derrotas e problemas? Quais as tensões existentes no processo político? Que universos simbólicos, sistemas epistemológicos e conhecimentos são confrontados? Quais os pontos de conflito nos processos culturais e que relações de poder desencadeiam? Há no processo político espaço para revitalização de questões materiais e simbólicas?

Recomendamos, enfim, a realização de pesquisas nessa perspectiva com vista a acrescentar elementos para pensarmos contra-hegemonia no campo do currículo e para praticarmos currículos contrahegemônicos no contexto contemporâneo das políticas curriculares.

OZERINA VICTOR DE OLIVEIRA é professora do Instituto de Educação da Universidade Federal do Mato Grosso (UFMT) e doutoranda no Programa de Pós-Graduação em Educação da Universidade do Estado do Rio de Janeiro (UERJ). Publicou: Proposições curriculares críticas para as séries iniciais do ensino fundamental - uma análise de seus limites e possibilidades. Revista de Educação Pública, Cuiabá: UFMT, v. 4, nº 5, jan.-jun. 1995, p. 391-401; $\mathrm{O}$ fazer pedagógico; redimensionamento e perspectivas. Revista de Educação Pública, Cuiabá: UFMT, v. 5, nº 7, jan.-jun. 1996, p. 325-328; Diferenciação e homogeneidade no currículo; as diferentes lógicas da diferença. Revista de Educação Pública, Cuiabá:
UFMT, v. 5, nº 8, jul.-dez. 1996, p. 337-346; com Cláudia Miranda, Multiculturalismo crítco, relações raciais e política cultural: a questão do hibridismo na Escola Sarã. Revista Brasileira de Educação. Rio de Janeiro: ANPEd, Campinas: Autores Associados, nº 25, jan.abr. 2004, p. 67-81. E-mail: ozerina@ig.com.br

DENISE DE SOUZA DESTRO é mestranda do Programa de Pós-Graduação em Educação da Universidade do Estado do Rio de Janeiro (UERJ) e professora de Educação Física da rede pública municipal de Juiz de Fora (MG). Publicou: A educação física nas escolas municipais de Juiz de Fora: um percurso de 25 anos (com outros autores), em CUNHA JÚNIOR, C. F. F., MARTIN, E. H., ZACARIAS, L.S. (orgs.) Educação física: narrativas e memórias em Juiz de Fora. Juiz de Fora: Ed. UFJF, 2003; Política curricular como política cultural: uma abordagem metodológica de pesquisa

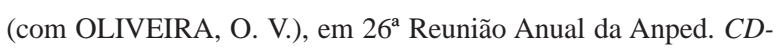
ROM, 2003; e Implicações entre relações políticas e pedagógicas nas imagens de corpo em livros didáticos de ciências, em Anais do XI Seminário de Educação: Educação e Trabalho. Cuiabá: UFMT, 2003. Participa da pesquisa "Currículo como entre-lugar identitário: raça, gênero e sexualidade no currículo de ciências", coordenada pela professora Elizabeth Fernandes Macedo, do mesmo programa.E-mail: dedestro@uol.com.br

\section{Referências bibliográficas}

BARRETO, E. S. S., (2000). Tendências recentes do currículo do ensino fundamental no Brasil. In: BARRETO, E. S. S. (org.). Os currículos do ensino fundamental no Brasil. Campinas: Fundação Carlos Chagas.

BALL, S. J., (1997). Educational reform: a critical and poststructural approach. Buckingham: Open University Press. , (1998). Cidadania global, consumo e política educacional. In: SILVA, Luiz H. (org.). A escola cidadã no contexto da globalização. Petrópolis: Vozes.

BOWE, R., BALL, S. J., (1992). Reforming education \& changing schools: case-studies in policy sociology. London/NY: Routledge.

COSTA, M. V., (1999). Currículo e política cultural. In: COSTA, M. V. (org.). O currículo nos limiares do contemporâneo. Rio de Janeiro: DP\&A.

GERALDI, C. M. G., (2000). Políticas curriculares oficiais e globais: algumas explicações sobre sua implantação no Brasil - o 
caso dos Parâmetros Curriculares Nacionais do Ensino Fundamental. COLÓQUIO SOBREQUESTÕES CURRICULARES POLÍTICAS CURRICULARES: CAMINHOS PARA FLEXIBILIZAÇÃO E INTEGRAÇÃO. 4. Actas... Braga, Portugal: Porto Editora/Centro de Estudos em Educação e Psicologia da Universidade do Minho, Fundação para a Ciência e Tecnologia/ Fundação Calouste Gulbenkian.

GIMENO SACRISTÁN, J., (1998). O currículo: uma reflexão sobre a prática. Porto Alegre: ArtMed. Tradução de Ernani F. da F. Rosa.

HALL, S., (1997). A centralidade da cultura: notas sobre as revoluções culturais do nosso tempo. Educação e Realidade, v. 2 , $\mathrm{n}^{\circ} 22$, p. 16-46.

MACEDO, E. F., (2002). Currículo como entre-lugar identitário: raça, gênero e sexualidade no currículo de ciência (mimeo.). MOREIRA, A. F. B., (1998). A crise da teoria curricular crítica. In: COSTA, M. V. (Org.). O currículo nos limiares do contemporâneo. Rio de Janeiro: DP\&A, p. 11-36.

, (2000). Estudos do currículo no Brasil: abordagens históricas. In: Actas do IV COLÓQUIO SOBRE QUESTÕES CURRICULARES - Políticas Curriculares: caminhos para flexibilização e integração [Porto Editora/Centro de Estudos em Educação e Psicologia da Universidade do Minho/Fundação para a Ciência e Tecnologia/Fundação Calouste Gulbenkian]. Braga - PT, p. 21-43.
MOREIRA, A. F. B., MACEDO, E. (2000). Currículo, políticas educacionais e globalização. In: PACHECO, J. A. (org.). Políticas de integração curricular. Braga, Portugal: Porto Editora. p. 99-126. SAID, E. W., (1978). Orientalismo - o Oriente como invenção do Ocidente. São Paulo: Companhia das Letras. Tradução de Tomas Rosa Bueno.

SANTOS, B. S., AVRITZER, L. (2002). Introdução: para ampliar o cânone democrático. In: SANTOS, B. S. (org.). Democratizar a democracia: os caminhos da democracia participativa. Rio de Janeiro: Civilização Brasileira.

SANTOS, B. S., (2002). Linha de horizonte: os processos da globalização. In: SANTOS, B. S. (org.). A globalização e as ciências sociais. São Paulo: Cortez. , NUNES, J. A., (2003). Introdução: para ampliar o cânone do reconhecimento, da diferença e da igualdade. In: SANTOS, B. S. (org.). Reconhecer para libertar - os caminhos do cosmopolitismo cultural. Rio de Janeiro: Civilização Brasileira, p. 25-68

SUÁREZ, D., (1995). Políticas públicas e reforma educacional: a reestruturação curricular na Argentina. In: SILVA, L. H., AZEVEDO, J. C. (orgs). Reestruturação curricular: teoria e prática no cotidiano da escola. Petrópolis: Vozes.

Recebido em setembro de 2003 Aprovado em agosto de 2004 


\title{
Resumos/Abstracts
}

\author{
Ozerina Victor de Oliveira \\ Denise de Souza Destro
}

\section{Política curricular como política cultural: uma abordagem metodológica de pesquisa}

Nosso objetivo é discutir concepções de política curricular para caracterizar uma abordagem metodológica de pesquisa que evidencie processos contra-hegemônicos em políticas curriculares. Pressupomos a centralidade da cultura em termos epistemológicos, a ampliação do campo político e a lógica espacial não-binária dos estudos pós-

coloniais. Desse exercício definimos política curricular como um processo histórico no qual diferentes protagonistas, imbuídos de seus projetos culturais/sociais, produzem tensões em torno da produção, circulação e consolidação de significados no currículo escolar, entendendo-a como uma política cultural. Sugerimos o deslocamento da abordagem metodológica hegemônica, ou seja, da perspectiva global/local para a perspectiva local/global, e consideramos um equívoco focalizar produção ou implementação, Estado ou cotidiano em pesquisas de política curricular. Enfim, pontuamos algumas questões que podem pautar estudos com essa perspectiva.

Palavras-chave: política curricular; política cultural; metodologia de pesquisa

\section{Curricular policy as cultural policy: a methodological research approach}

Our objective is to discuss conceptions of curricular policy to characterise a methodological research approach that provides evidence of counter-hegemonic processes in curriculum policies. We presuppose the centrality of culture in epistemological terms, the broadening of the political field and the non-binary spatial logic of post-colonial studies. Based on this exercise we define curricular policy as an historical process in which different protagonists, imbued with their cultural/social projects, produce tension around the production, flow and consolidation of meanings in the school curriculum, understood as a cultural policy. We suggest the transposition of the hegemonic methodological approach, that is, from the global/local perspective to the local/global perspective and consider it an error to centre on production or implementation, State or daily life in research on curricular policy. Finally, we point to questions that can guide studies within this perspective.

Key-words: curriculum policy; cultural policy; research methodology 